\title{
ON SEMI-INVARIANT SUBMANIFOLDS OF A NEARLY $r$-PARACOSYMPLECTIC MANIFOLD
}

\author{
MOHAMMAD NAZRUL ISLAM KHAN
}

\begin{abstract}
The purpose of the present paper is to study semi-invariant submanifolds of a nearly $r$-paracosymplectic manifold. We also investigate totally $r$ paracontact umbilical semi-invariant submanifolds of a nearly $r$-paracosymplectic manifold. Moreover, we construct an example of a nearly $r$-paracosymplectic metric manifold which is not $r$-paracosymplectic.
\end{abstract}

MSC 2010. 53B25, 53C25, 53D15.

Key words. Semi-invariant, submanifold, $r$-paracontact, umbilical, cosymplectic.

\section{REFERENCES}

[1] T. Adati, An almost r-paracontact Riemannian manifold and an almost product Riemannian manifold, Tensor, 43 (1986), 239-247.

[2] M. Atceken, Geometry of semi-Invariant submanifolds of a Riemannian product manifold, Math. Morav., 14 (2010), 23-34.

[3] A. Bejancu, On semi-invariant submanifolds of an almost contact metric manifold, An. Ştiinţ. Univ. Al. I. Cuza Iaşi. Mat., 27 (1981), 17-21.

[4] A. Bejancu and Papaghiuc N., Semi-invariant submanifolds of Sasakian manifold, An. Ştiinţ. Univ. Al. I. Cuza Iaşi. Mat., 27 (1981), 163-170.

[5] D. Blair, Riemannian geometry of contact and symplectic in $2 n+1$ dimension, Progress of Mathematics, 203, Birkhäuser, Boston/Basel/Berlin, 2002.

[6] C. Calin, M. Crasmareanu, M.I. Munteanu and V. Saltarelli, Semi invariant $\xi^{\perp-}$ submanifolds of generalized quasi-Sasakian manifolds, Taiwanese J. Math., 16 (2012), 2053-2062.

[7] L.S. Das, R. Nivas and M.N.I. Khan, On semi-invariant submanifolds of conformal $K(\xi)$-contact Riemannian manifold, Algebras, Groups and Geometries, 23 (2006), 291296.

[8] H. Endo The curvature tensor of nearly cosymplectic manifolds of constant $\phi$-sectional curvature in $2 n+1$ dimension, An. Ştiinţ. Univ. Al. I. Cuza Iaşi. Mat., 2 (2005), 439-454.

[9] K. I. Erken, P. Dacko and C. Murathan, Almost $\alpha$-paracosymplectic manifolds, J. Geom. Phys., 88 (2015), 30-51.

[10] Z. Olszak, On almost cosymplectic manifolds, Kodai Math. J., 3 (1981), 239-250.

[11] S.K. Srivastava and A. Sharma, Geometry of $\mathcal{P} \mathcal{R}$-semi-invariant warped product submanifolds in paracosymplectic manifold, J. Geom., 108 (2017), 61-74.

The author wishes to express his sincere thanks and gratitude to the referee for his/her valuable suggestions towards the improvement of the paper.

DOI: $10.24193 /$ mathcluj.2018.1.06 
[12] I. Stere, On CR-submanifolds of a nearly cosymplectic manifold, Tensor (N.S.), 46 (1987), 291-295.

Received April 25, 2017

Accepted August 26, 2017
Qassim University, College of Computer Department of Computer Engineering Buraidah-51452, P.O. Box 6688

Saudi Arabia

E-mail: m.nazrul@edu.qu.sa

E-mail: mnazrul@rediffmail.com 